\title{
Guaranteed O\&M for Solar Plants in Vietnam - A review \& Proposal on Guaranteed O\&M service to foster sustainable energy generation by maximizing solar energy production and safeguarding investment.
}

\author{
Surender Rangaraju, Osama Isaac, Phu Le Vo, Khuong Vinh Nguyen, Arjun A
}

\begin{abstract}
Vietnam government has framed strategic goals to ensure that most of the households shall have access to Renewable energy in 2020. To achieve this, the government has mobilized all the resources in the society that will facilitate to provide energy at affordable price. The Vietnam government has turned its focus not just on renewable energy generation but a sustainable and low-cost energy generation that will help to boost the economic growth. Solar energy generation is one of the promising solutions that the Vietnam government relies on to produce cost effective renewable energy. The government has projected that share of solar power generation in 2020 will be around $0.5 \%$ and planning to gradually increase it to $6 \%$ by 2025 and to $20 \%$ by 2030. (Minister Of Industry and Trade, 2015) Though the Solar energy generation is the most trusted and reliable solution to generate renewable energy at an affordable cost, poor maintenance of solar panels can ruin the entire dream of the nation in achieving energy independence. The burden involved in maintaining the solar panels and retaining the energy yield over the years has been major reasons for lack of investors interest. One of the most important ways to guarantee that the solar power system generates the maximum electricity is through operation and maintenance (O\&M). Consistent monitoring of the solar PV panels is the foundation of a solar power plant's operation and maintenance. This may be accomplished by maintaining the plant infrastructure and equipment with the objective of extending the life of the equipment by preventing excessive depreciation and impairment. This allows the solar power plant to generate the most energy possible throughout the course of its operational life, perfectly matching the interests of developers, clients, and investors. This article focuses on a newfound O\&M model that fits for Vietnam's solar energy market to address the Operation and Maintenance issue and to maximize energy generation and to safeguard investment. This model will also facilitate to attract more investments for the solar energy projects in Vietnam by promising guaranteed power yield.
\end{abstract}

Index Terms- O\&M for Solar farms, Solar Panel maintenance, Guaranteed solar power Yield, Robots in Solar energy, PV panel cleaning robot, Guaranteed O\&M for Solar

Surender Rangaraju, Department of Business and Accountancy Lincoln University College - Malaysia

Osama Isaac, Faculty of Business and Accountancy - Lincoln University College - Malaysia.

Phu Le Vo, Faculty of Environment and Natural Resources, Ho Chi Minh City University of Technology - Vietnam.

Khuong Vinh Nguyễn, RMIT University, Saigon South - Vietnam.

Arjun A, Department of Instrumentation and Control Engineering, PSG College of Technology - India farms, AI and IoT in Solar Farms, Low-cost solar energy generation Solar Plants, Vietnam

\section{I.INTRODUCTION}

In recent years Vietnam has achieved improvement in developing social-economic condition of its people and continues to focus on sustainable development methods to sustain and improve the living condition of the people. In 2017, solar energy plays practically little part in Vietnam's energy strategy. However, by the end of 2019, Vietnam has surpassed Malaysia and Thailand in terms of solar panel capacity installation in Southeast Asia. The country presently has 5 Gigatonnes $(\mathrm{GW})$ of solar projects under construction, significantly surpassing the target of $1 \mathrm{GW}$ by 2020. In 2017, total solar power generated in Vietnam was 8 MW, with total electricity produced in 2020 expected to be 16,504MW.(IRENA (2021) 43) This rapid increase in solar capacity reflects Vietnam's interest in renewable energy, particularly solar energy. The projected capacity for renewable energy in 2045 is $121 \mathrm{GW}$, however by January 2021, the entire installed capacity, including capacity currently in operation and proposed capacity to be added to planning, has already reached $180 \mathrm{GW}$.
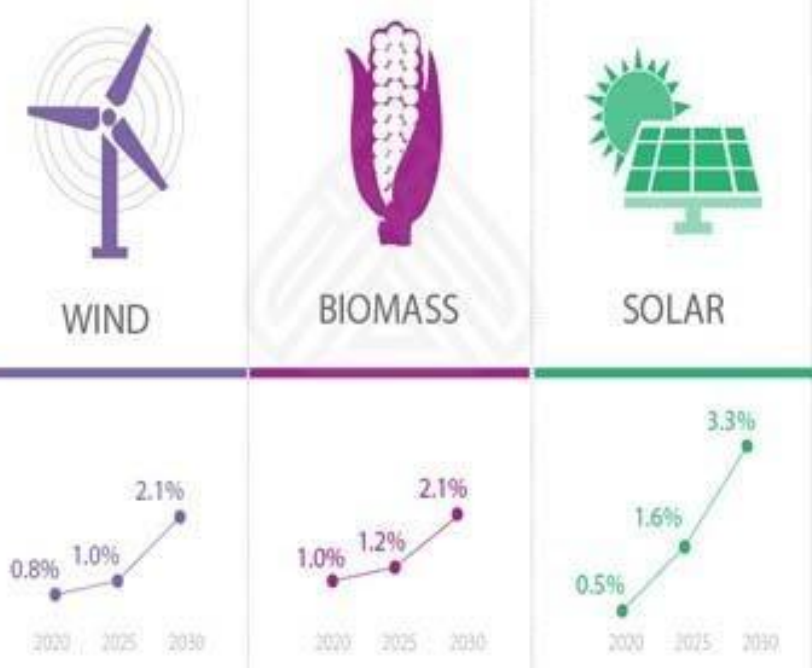

There are still debates going on if Solar energy generation is appropriate solution to address the rising power demand in Vietnam. Land is a scares resource in Vietnam and this expensive resource can be well utilized for agriculture and to build house rather than installing land based solar farms. The land based solar farms can also degrade the fertility of the soil. Besides, scares resource like water is required more often to clean the solar panels and regular maintenance and monitoring activity is essential, if not it will drastically 

sustainable energy generation by maximising solar energy production and safeguarding investment

reduce the yield of power generation. The need of regular maintenance activity and use of scares resources incurs a huge cost and until now in Vietnam the O\&M services never guarantees on the yield of the solar panels. Another huge drawback is most of the solar projects in Vietnam are not provided with Linear Performance Guarantee (LPG) or Guaranteed Yield as it is a new concept developed couple of years before. (Solar Mango, 2016) Due to these facts the investors are uncertain about their Return of Investments and gradually losing confident on investing in solar energy projects in Vietnam. Solar PV panels does not need much complicated maintenance activities, when compared with other renewable energy solution but in order to get accurate ROI it is essential to focus on effective operation and maintenance service that guarantees solar energy yield. The performance warranty will offer assured power output throughout the year, and if the yield lowers for any reason, the loss will be reimbursed by the O\&M service provider. Hence Guaranteed Yield O\&M services will be the best option to adopt for existing and upcoming new solar projects in Vietnam as it will safeguard investments and boost confidence among the investors.

\section{II.UNDERSTANDING SOLAR PANEL WARRANTY AND POWER WARRANTY}

Both solar panel warranty and power warranty is provided by the manufacture of solar panels. The panel warranty also known as product warranty generally covers any issues that arise due to manufacturing defect in the product. If a PV panel has experienced any manufacturing problems like poor soldering, bad workmanship, etc., within the warranty period, then the manufacturer will replace the product according to the warranty policy. (LESLIE HANCOCK, 2017) The power warranty is also provided by the product manufacturer after calculating the degrading rate over years. This type of warranty has been provided in recent years by manufacturers to furnish the customer with clear sense of minimum power that the PV panel will be capable of generating during the PV panel lifetime specified by the manufacturer. If the PV panel output drops more than the assured output, then the manufacture will either refurbish, repair or change the PV panel depending upon the warranty policy. (LESLIE HANCOCK, 2017) The figure 2 (Standard Guarantee by PV Manufacturer) shows the standard guarantee in which the performance assured by the manufacture drastically drops after 10 years of raising concerns about ROI and the low profitability.

\section{Standard GUARANTEE}

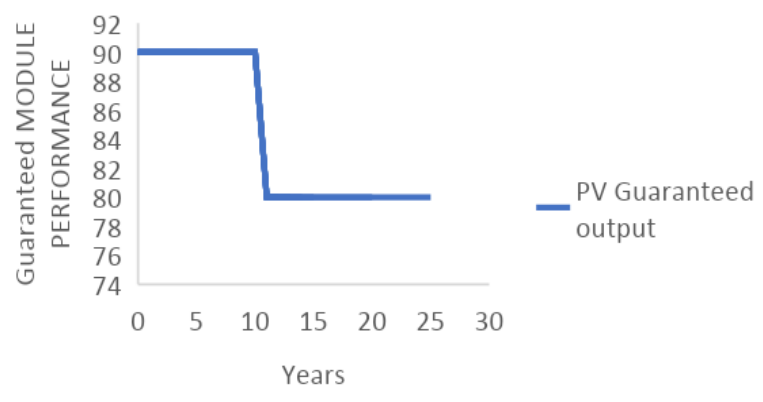

In order to be competitive and to sustain the heavy competition in the PV manufacturing sector, the linear performance guarantee has been adopted by several manufactures. According to a PV manufacture the actual power output of the new PV panels cannot deviate by $3 \%$ from the specified rate. On average if the power output degrades by $0.7 \%$ then by 10 years the expected output from PV panels should be $90 \%$ as opposed to standard guarantee of $80 \%$. (Solar World, n.d.) This Linear performance guarantee approach has helped to gain the investor confidence and have facilitated to calculate the project ROI.

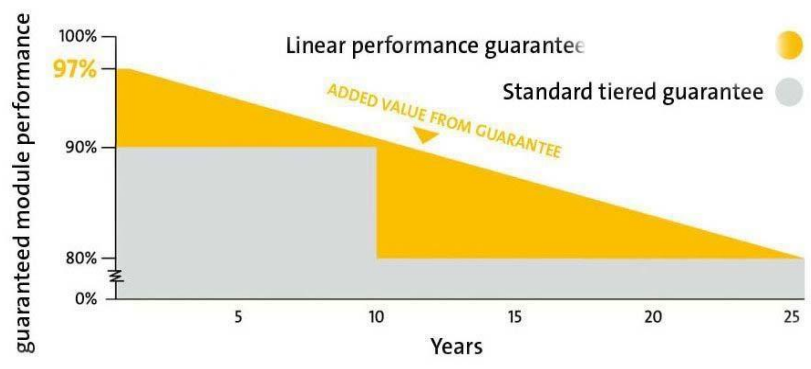

\section{III.INSTALLER WARRANTY}

The installer warranty is provided by the EPC company. Different components like inverters, PV panels, cables and mounting hardware will have product warranty from the respective manufactures. On top of it the installer will provide additional warranty to cover the damage or loss incurred during the deployment phase. This warranty is a short-term warranty and, in most cases, expires as soon as the systems is operational.

\section{IV.WHAT IS GUARANTEED PERFORMANCE WARRANTY}

Every year, the quantity of power produced by a solar panel decreases gradually. That is true to various degrees for all solar panels. A frequent approach in the solar energy business is to ensure that the panels will not lose more than $10 \%-20 \%$ of their power production capability during the first 25 years, which is an important advantage of a decent solar panel warranty. In other words, panel manufacturers often promise that their panels will produce energy at 80-90 percent of their power output rating after 25 years. The product and power warranty provided by the manufacturer comes into role only when the product is defective or not producing the expected output as promised by the manufacture. This provides a relief to the investors and helps to calculate the accurate ROI. This does not mean the invested capital is safe. There are several unforeseen situations like natural calamities, act of god, etc., that can collapse the entire investment. The performance warranty will provide guaranteed power output over the year and for some reasons, if the yield drops then the loss would be compensated by the O\&M service provider. Ameri-solar, a solar panel producer, guarantees an 80 percent performance output after 25 years, with certain manufacturers achieving slightly better. In a nutshell the Guaranteed O\&M service will assure the performance of the photovoltaic and other system to produce guaranteed power output under any circumstance. The system performance may be enhanced by 
utilising numerous high-performance components, such as $\mathrm{SiC}$ gate drivers or SiC inverters (Nguyen \& Nguyen Quang, 2018). High performance can be achieved through a systematic approach and integrating state-of-art technology to operation and maintenance activities.

\section{V.OVERVIEW ON GUARANTEED O\&M SERVICES}

The Guaranteed O\&M main aim is to convert nonprofitable solar farm projects into profitable and sustainable energy generating projects by using state of art technology to optimize the existing infrastructure. This would require long-range strategic planning and involve innovative technology to enhance the productivity and revenue of under-performing solar projects. The GO\&M focuses on some key service elements that are very crucial to maintain and enhance the productivity of a solar farm. If the prior EPC business delivered a poor quality product and left after 1-5 years, and the project owner would like an alternative firm to undertake the GO\&M for them. It gets difficult to do so. As a result, the first and most crucial step is to audit the present system. After auditing the present existing system, the extent of percentage to perform for the GO\&M can be finalized. These key service elements should be structured in a proper way to facilitate effective Guaranteed O\&M service. They are explained below:

Structuring Solar Plant monitoring and supervising Team

The Solar plant will be handed over to the O\&M team post completion of the deployment and commissioning activities. The engineering, procurement, and construction contractor should ensure that the handover process is done properly, and the O\&M team have access to all the documents and access to full data that is vital for maintaining the solar plant. For effective GO\&M there should be at least 3 level of support levels a) L1 - Level 1 b) L2-Level 2 c) L3-Level 3

The L1 team will comprise of members in monitoring and field team. With the help of alerts from monitoring systems the L1 team will be able to raise trouble tickets and will involve in resolving the incident remotely using some system command and that will also include soft reboots. In case if the remote troubleshooting fails then the L1 field team will move to the field to record the failure reasons and will involve in troubleshooting the issue. If the prior EPC provider produced a poor quality product, it is acceptable to have the GO\&M with the present system after auditing. However, when the system was supposed to run GO\&M, if the system failed due to lightning, the team had to devise a repair strategy for the system using surge protectors and other technologies. The filed team will involve in change of hardware if required, hard reboot of system and other activities required to resolve the incident. The entire process is recorded, and the ticket is closed after successfully resolving the issue. The $\mathrm{L} 1$ monitoring team is responsible for recording RCA (Route Cause analysis) which will help to fix bugs, update versions and also help improve product quality. The L1 team will also involve in upgradation activities and will be well-versed in using innovative technology like $\mathrm{Ai}$, robots and drones that will help to carryout the monitoring and maintenance activities in an efficient manner. The L2 team will include senior members in monitoring and filed team. The issues that the L1 team unable to resolve will be escalated to the L2 team. The L2 team will be experts and certain activities are carried out only by the L2 team such as executing core system commands and activities that need serious attention and skills as any outage may create severe consequence.

The L3 team will comprises more senior members in the level of project managers, who are responsible for providing Advance Support, which includes analyzing the raw data from the solar plant and take preventive measures to avoid major breakdown and outrages. The L3 team will also work with L1 team in order to identify RCA for the repeated and severe failures and discuss with vendors, suppliers to improve the quality and update versions that helps to minimize the downtime and enhance the performance of the solar plant.

Integrating IoT, Artificial Intelligence and Drones to Solar Farms:

Internet of things are already part of our daily life nowadays. IoT integrated with Artificial Intelligence (AI) can play a vital role in the effective maintenance of Solar farms by collecting, storing, and analysing data. The data size is one of the problems with $\mathrm{AI}$ in this case. It must be "big data," yet the data is insufficient. Data acquisition is causing issues for businesses. Drones can ease the inspection process of solar farms by provide high resolution images of solar panels and connecting wires with accurate data that is required for the solar farm maintenance activities.

Drones play critical role in deployments and maintenance of solar farms by providing reliable and affordable information. The maintenance team can get real-time data through arial image and detect the flaws that is affecting the performance of the solar panels. The image acquired from the drones can be processed with AI to determine if the faults are caused by physical issues such as dust, cracks, delamination or system related issues like inverter or cable fault. (DJI, n.d.) Drones in Vietnam require several administrative clearances before they may fly for the first time. As a result, while focusing on the Vietnam market, another alternative may be something akin to an Automated Guided Vehicle (AGV).

The use of AI, IoT, Drones can increase the efficiency and save time for maintenance team and thus plays a special role in the guaranteed operation and maintenance activity by providing wide range of inspection and surveillance tasks. (SKYLINE DRONES, n.d.)

\section{VI.OVERVIEW ON INSURANCE POLICY}

A good insurance policy that can cover solar farm under operation stage will facilitate the O\&M providers to compensate for the loss incurred due to damage, theft, removal of equipment's for maintenance or repair and loss incurred due to natural calamities like flood and storms. (marsh commercial, n.d.)

In some developed countries like United Kingdom, Australia and Canada there are insurance that can cover solar farms right from installation until operational phase. These solar farm insurance policy covers wide range of risks like loss of revenues, reinstallation and decommissioning, delay in production, logistic delay and environmental liabilities. (marsh commercial, n.d.). The premium of the 


\section{Guaranteed O\&M for Solar Plants in Vietnam - A review \& Proposal on Guaranteed O\&M service to foster sustainable energy generation by maximising solar energy production and safeguarding investment}

coverage is around $\$ 1180$ annually.

These types of insurance are not quite famous in Vietnam solar energy sector, and they can complement the Solar farm O\&M services if they are made available for the Vietnam solar energy projects.

\section{VII.LIMITATION IN IMPLEMENTING GUARANTEED O\&M CONCEPT}

Because the adaptation of technology and insurance policies must be in accordance with government policies and legal framework, it is extremely difficult to adopt or introduce new concepts that may backfire or incur financial losses in the Vietnam government's policy towards the solar energy sector. The huge challenging point of GO\&M stems from the issue of incorporating technology into O\&M tasks.

When integrating new systems with legacy systems that have been in place for many years, interoperability difficulties might arise. The GO\&M can be done relatively easily if it is a stand-alone system, such as a photovoltaicbased energy system for mobile device chargers (Nguyen \& Nguyen Quang, 2015). For the solar farm, however, there would be a trade-off since revenues would grow while technical affordability and feasibility would be more difficult.

\section{IX.CONCLUSION}

Solar Farm O\&M activity is a crucial task that cannot be neglected in order to keep the asset operational. The investors are very particular when it comes to ROI. To safeguard the investment and interest of the investor the O\&M services must guarantee the production of solar energy.

The state-of-art technologies like IoT, Artificial Intelligence, Robotics and drones can reduce the cost monitoring and facilitates in effective O\&M services. The addition of ESS (Energy Storage System) can also be a best option to avoid energy wastage. The Guaranteed O\&M services framework will help to collect quality data that can be used for the stable operation of the solar farms thus resulting in Guaranteed output.

\section{REFERENCES}

1. DJI, n.d. DJI ENTERPRISE. [Online] Available at: https://enterprise.dji.com/news/detail/drones-for-solarfarminspections\#: :text=Drones\%20are\%20continuously\%20being\% 20used,when $\% 20$ compared\%20to\%20traditional\%20methods. [Acces sed 7 June 2021].

2. LESLIE HANCOCK, 2017. Solar panel warranties vs. system performance guarantees: Apples and oranges. [Online] Available at: https://businessfeed.sunpower.com/articles/solar-panelwarranty-vs-performance-guarantee [Accessed 17 January 2020].

3. Marsh commercial, n.d. solar-panel-and-projects. [Online] Available at: https://www.marshcommercial.co.uk/forbusiness/renewable-energy-insurance/solar-panel-and-projects/ [Accessed 17 June 2021].

4. Minister Of Industry and Trade, 2015. Approving the Viet Nam's Renewable Energy Development Strategy up to 2030 with an outlook to 2050.2 [Online] Available https://www.mzv.cz/public/1b/a6/7a/1810646_1462225_Strategy_on_ Renewable_Energy_Decision_2068_ENG_2015_11_25.pdf [Accessed 14 January 2020].

5. SKYLINE DRONES, n.d. drone-benefits-in-photovoltaic-solar-farms. [Online]

Available at: https://skylinedrones.ro/drone-benefits-in-photovoltaicsolar-farms/ [Accessed 7 June 2021].
6. Solar Mag, 2019. Vietnam Solar Profile: Energy, and an Economy, in Transition. [Online] Available at: https://solarmagazine.com/solar-profiles/vietnam/ [Accessed 17 January 2020].

7. Solar Mango, 2016. Linear Performance Guarantee Works for Solar Panels. [Online] Available at: http://www.solarmango.com/2016/08/07/linearperformance-guarantee-works-solar-panels/ [Accessed 15 January 2020].

8. SolarWorld, n.d. SolarWorld Panels. [Online] Available at: http://www.sunwavesolar.net/Solarworld_Panels.html [Accessed 15 January 2020].

9. UNDP, 2015. Formulation of the Action Plan for Implementation of Viet Nam's Renewable Energy Strategy. [Online] Available at: https://www.undp.org/content/undp/en/home/search.htmlq=Vietnam+ Renewable+Energy+development+project+to+2030+with+outlook+to +2050 [Accessed 14 January 2020]. 